\title{
BIM-LCA INTEGRATION FRAMEWORK FOR SUSTAINABLE ROAD PAVEMENT MAINTENANCE PRACTICES
}

\author{
CRISTINA ORETO ${ }^{1}$, SALVATORE ANTONIO BIANCARDO ${ }^{1 *}$, ROSA VEROPALUMBO ${ }^{1}$, NUNZIO \\ VISCIONE $^{1}$, FRANCESCA RUSSO $^{1}$, FRANCESCO ABBONDATI $^{2} \&$ GIANLUCA DELL'ACQUA $^{1}$ \\ ${ }^{1}$ Department of Civil, Construction and Environmental Engineering (DICEA), Federico II University of Naples, \\ Naples, Italy \\ ${ }^{2}$ Department of Engineering, University of Naples Parthenope, Naples, Italy
}

\begin{abstract}
The latest advancements in road asphalt materials and construction technologies have increased the difficulty for engineers to select the appropriate pavement design solution with consideration of life cycle assessment (LCA) methodology. On the other hand, infrastructure building information modeling (BIM) tools allow practitioners to efficiently store and manage large amounts of data, supporting decision making in road asphalt pavement design and management. This research contributes to setting up a dynamic LCA tool for the specific evaluation of designed road asphalt pavement solutions involving alternative materials and advanced recycling technologies; the tool is structured to minimize the need of input data by the designer, that are usually unknown during the early design stage, and automate the entire LCA calculation process to reduce the designer efforts and avoid any errors during data transcription. A traditional BIM workflow was integrated with additional user-defined property sets to simultaneously compute the environmental impact of the entire life cycle of the asphalt pavement, and dynamically update the result basing on the design thickness of the pavement layers, the specific features of materials and an external database of several life cycle impact category indicators that can be edited and updated gradually during more advanced design stage. The proposed BIM-LCA aims to be a practical and dynamic way to integrate environmental considerations into road pavement design, encouraging the use of digital tools in road industry and ultimately supporting a pavement maintenance decision-making process oriented toward circular economy.
\end{abstract}

Keywords: BIM, LCA, pavement maintenance.

\section{INTRODUCTION}

Road networks play a crucial role in the economic development of communities; at the same time, the construction and maintenance of road asphalt pavements during their service life is extremely resource-consuming [1], generates high volumes of waste and involves long supply distances, contributing highly to global warming [2].

In this context, the life cycle thinking approach has been identified as a key methodology to support the selection of sustainable design alternatives through a comprehensive decisionmaking process, which involves environmental, social and cost indicators [3].

In particular, life cycle assessment (LCA) is a standardized and consolidated methodology that can help evaluate the potential environmental impacts of the life cycle of a road pavement solution. Researchers have been comparing, through LCA methodology, the environmental impacts of traditional road asphalt mixtures, made up of natural aggregates and bitumen and mixed at high temperature $\left(170^{\circ} \mathrm{C}-180^{\circ} \mathrm{C}\right)$, with alternative bituminous materials using waste recycled as secondary raw materials in substitution of natural aggregates [4] or employing cold production technologies [5], where bitumen emulsion is adopted instead of bitumen to enhance the workability of the mixture at $50^{\circ} \mathrm{C}-60^{\circ} \mathrm{C}$.

However, since performing a LCA is often complex, and requires time and large amounts of data, Van Eldik et al. [6] pointed out that it is often performed at the end of the design 
phase when the design choices are already taken and therefore, it is too late to incorporate the environmental impact in a broader decision-making process.

In recent years, the need to apply the life cycle approach to the design and maintenance of road infrastructures has further promoted the use of building information modeling (BIM)based tools, moving forward from the 3D visualization [7], [8] and interference detection [9] to the integration of more advanced information in the design framework to actively support design and management tasks [10]. So, in its most developed form, BIM should be observed as a digital and smart representation of data-enriched objects created through the collaboration between the involved parties to provide feedback at the earliest possible time, improve the decision-making process and increase project efficiency at all its stages [11]. For this reason, BIM can effectively help designers in storing, analyzing and reporting the information related to the life cycle environmental sustainability of a project.

Looking at the integration of BIM and LCA in the infrastructure sector, few efforts have been identified for road infrastructures. Liu et al. [12] proposed a theoretical framework for introducing a sustainability infrastructure rating system in a BIM environment that helps establish the consistency of each element's functional and physical attributes in relation to a set of sustainability requirements. Antón and Díaz [13] introduced two approaches for integrating LCA and BIM; the first involves extracting information from BIM model to calculate the LCA performance, obtaining higher accuracy but also higher complexity of the BIM model, and the second requires inputting manually the environmental properties of the materials into the BIM, which is simpler but less effective in terms of automatization and dynamism of the information. Concerning the information exchange between the BIM model and LCA platform calculations, Kaewunruen et al. [14] enriched the model information with the embodied carbon footprint of the lifecycle of different elements of a bridge project, each one identified by their constituent materials, obtaining a quantitative estimation of the environmental impacts of the model elements that were manually transferred from the BIM environment to the LCA tool. Lastly, Slobodchikov et al. [15] developed an Autodesk Civil3D application that focuses on the calculation of the global warming potential (GWP) impact indicator of a road asphalt pavement basing on the material volumes of each layer and the construction operations scheduling gathered from the BIM model, also returning a visual representation in a color scale of the GWP of each element of the road pavement.

Despite the increasing interest in the possibilities offered by the integration of sustainability assessment of road construction projects in the BIM environment, the following have been identified as the main topics that need improvements:

1. the identification of specific sets of parameters, beyond the simple element/material identifier, that enable the integration of more accurate LCA, also allowing a distinction between traditional and innovative or recycled materials;

2. the improvement of the flexibility of BIM-LCA tools to let the user apply changes and update project-specific LCA data;

3. the automatization of LCA calculations and bidirectional exchange of information between the BIM platform and the LCA tool;

4. the calculation of a greater number of LCA impact category indicators indicating the environmental issues of the project not only in terms of global warming and climate change. 
This research work aims to fill some of the mentioned gaps that still hinder the possibility to apply LCA methodology to an asphalt pavement using BIM workflows. In particular:

- a methodological framework for the extension of the informative content of the BIM objects, including the specific mix composition, asphalt production technology, the productivity of the construction operations and the supply distances of raw/semi-finished/ finished materials;

- a flexible and dynamic tool useful to estimate the life cycle environmental impact indicators (EIIs) of the asphalt layers of a pavement solution basing on the information extracted from the BIM model (materials volumes and the mentioned custom property sets regarding the characteristics of the asphalt mix design for base, binder and wearing course), is provided.

The script is intended as a quick tool to automatically provide a report of several environmental impact category indicators of an asphalt pavement design solution, also allowing the selection of alternative materials and technologies from a default library of unit processes, eventually editable by the users to include project-specific assessments. The obtained information can be also used to support the comparison of traditional and alternative pavement design configurations, other than convey into further BIM-integrated decision-making frameworks.

\section{METHODS}

\subsection{I-BIM modeling of a road pavement}

The workflow shown in Fig. 1 begins by following the traditional BIM modeling steps for linear infrastructures. In the present work, the creation of the 3D BIM model of the road asphalt pavement section was carried out using Autodesk Civil 3D, through which the following elements were created:

1. terrain surface of the area surrounding the project;

2. horizontal alignment and vertical profile (representation of the planimetric and altimetric elements of the road section);

3. road pavement section assembly, consisting of four overlapping layers of a flexible road pavement, namely wearing course, binder, base and subbase layers;

4. road corridor, which is the $3 \mathrm{D}$ element made up of the previous elements, from which the quantity take-off can be estimated basing on the assigned geometry of the 3D solids.

On this way, an accurate model containing the elements of the pavement solid geometry was created to be further integrated with user-defined property sets, which introduce several customized, controllable and dynamically editable parameters needed to perform LCA calculations, that are introduced in the Results Section.

\subsection{LCA applied to road pavements}

LCA methodology, standardized internationally with EN 14040 and EN 14044, is a technique used to assess environmental impacts associated with a system's life cycle. 


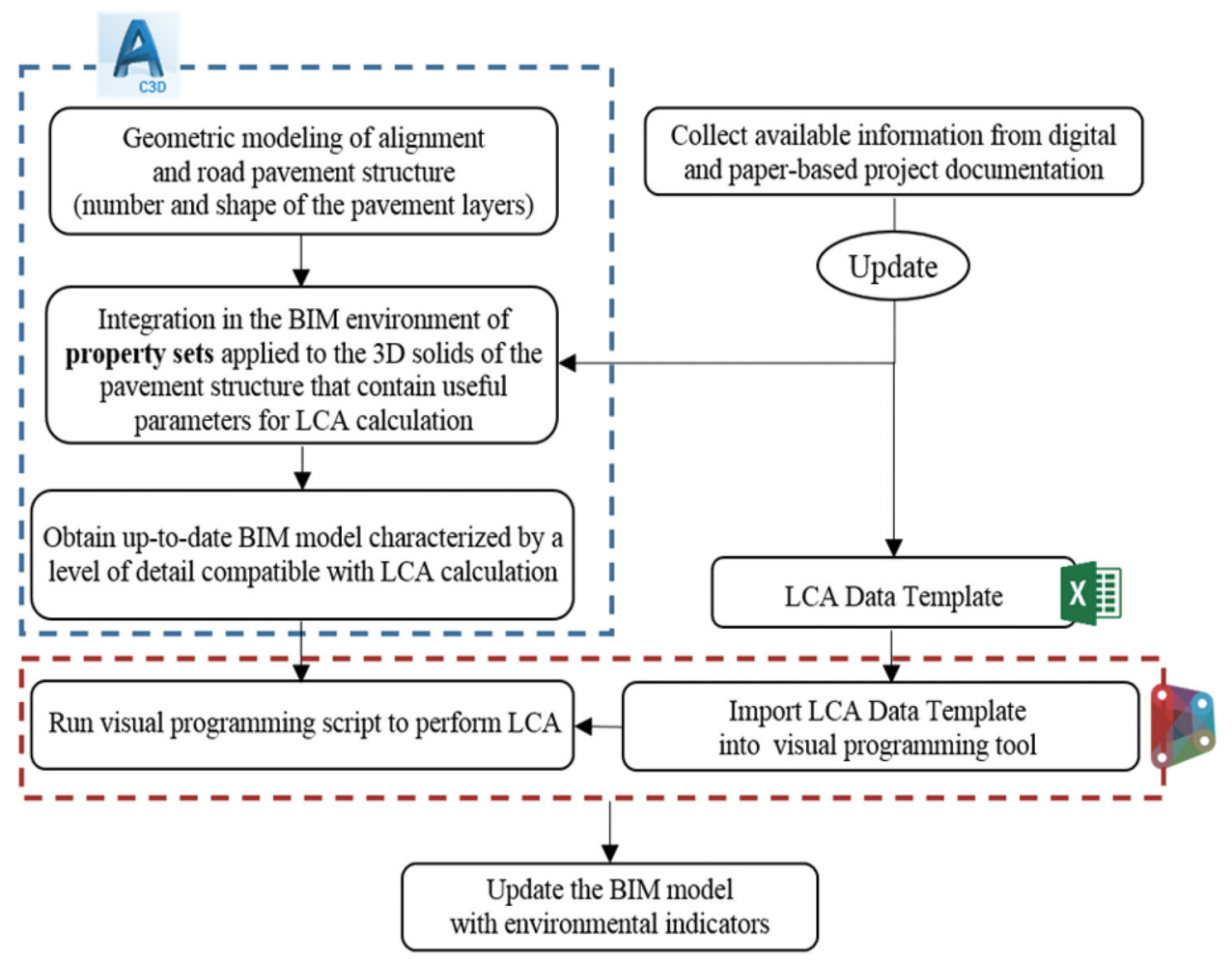

Figure 1: LCA-BIM workflow.

In the present BIM-LCA framework, the main goal of the analysis is to provide the overall environmental impact category indicators of the life cycle of an asphalt pavement solution, included in the road pavement system with specific user-defined features and boundary conditions. Two alternative technologies are available for the construction/maintenance treatment of each layer: hot in-plant production and cold in-place recycling with reclaimed asphalt pavement. So, the functional unit of the present LCA methodology is the constructed/ maintained road asphalt pavement (wearing, binder and base course) of the project corridor (with the chosen width, length and thickness of each layer).

The system under analysis has been modeled according to the following disaggregates processes included in the system boundary:

- the production of raw/semi-finished materials, such as coarse aggregates, sand, fillers, bitumen, cement,

- the production of hot asphalt mixtures in asphalt plant (which has not been considered when dealing with cold recycled layers),

- the construction of the road pavement layers,

- the milling and disposal of the existing asphalt layers and

- the transportation phases, which involve all of the mentioned processes.

The input and output flows of each of these processes were estimated using data from Ecoinvent 3 database [16], European Bitumen Association [17] and U.S. Environmental Protection Agency (2004) [18]. 
For each of the mentioned unit disaggregated processes, the impact assessment phase was conducted using SimaPro $9 \circledR$ software. The impact category indicator results were expressed according to the ReCiPe [19] midpoint impact assessment method, which proposes the following set of EIIs: global warming (GWP), stratospheric ozone depletion (ODP), ionizing radiation (IR), damage of ozone formation on terrestrial ecosystems (OFT) and human health $(\mathrm{OFH})$, fine particulate matter formation $(\mathrm{PM})$, terrestrial acidification $(\mathrm{A})$, freshwater eutrophication (FE), marine eutrophication (ME), terrestrial, freshwater and marine ecotoxicity (T-ECO, F-ECO and M-ECO), human carcinogenic (CT) and non-carcinogenic toxicity (NCT), land use (LU), mineral resource scarcity (MR), fossil resource scarcity (FR) and water consumption $(\mathrm{W})$.

The overall environmental impact of the life cycle of each pavement layer was calculated according to Equation 1.

$$
\begin{aligned}
\overline{E I I}_{T O T}= & \sum_{i} Q \cdot d \cdot M_{i} \cdot \overline{E I I}_{M, i}+Q \cdot d \cdot f \cdot \overline{E I I}_{P}+K_{j} \cdot P_{j} \cdot \overline{E I I}_{C, j} \\
& +W \cdot \overline{E I I}_{D}+\sum_{p} F_{p} \cdot D_{p} \cdot \overline{E I I}_{T}
\end{aligned}
$$

where

- $E I I_{\text {TOT }}=$ set of $E I I$ of the life cycle of the asphalt layer;

- $Q=$ volume of the asphalt layer $\left[\mathrm{m}^{3}\right]$;

- $d=$ density of the asphalt layer $\left[\mathrm{t} / \mathrm{m}^{3}\right]$;

- $M_{i}=$ percentage by the weight of the mixture of the $i$ th component (aggregates, sand, filler, bituminous binders and cement);

- $\mathrm{EII}_{M, i}=$ set of EII of the production of 1 tons of raw and semi-finished materials;

- $f=$ dummy variable that is equal to 1 if the mixture is hot-produced in plant, 0 if the cold in-place recycling technology is exploited;

- $E I I_{P}=$ set of EII of the hot in-plant production of 1 tons of asphalt mixture;

- $K_{j}=j$ th laid quantity, expressed as the amount of mixture in the case of hot asphalt mixture laying [t], or as the pavement surface in the case of cold in-place recycling $\left[\mathrm{m}^{2}\right]$;

- $P_{j}=$ productivity of the $j$ th construction technology, expressed in $\mathrm{t} / \mathrm{h}$ of $\mathrm{m}^{2} / \mathrm{h}$ depending again on the construction technology;

- $E I I_{C, j}=$ set of $E I I$ of the construction of 1 tons of hot asphalt mixture or 1 square meter of cold recycled pavement;

- $W=$ amount of waste produced from the milling of the existing asphalt pavement [t];

- $E I I_{D}=$ set of EII of the disposal of 1 tons of asphalt waste;

- $F_{p}=$ material flow (raw/semi-finished/finished materials) of each $p$ th disaggregated process that requires transportation between the $p$ th facility to the next process of the life cycle $[\mathrm{t}]$

- $D_{p}=p$ th transportation distance $[\mathrm{km}]$;

- $E I I_{T}=$ set of EII of the transportation process of 1 tons of material per $1 \mathrm{~km}$.

\section{RESULTS AND DISCUSSION}

The framework here presented and discussed provides the integration of LCA methodology applied to the road asphalt pavement and the automation of such LCA calculations in the 
BIM environment. First, the information content required for the LCA calculations is collected from the BIM model. Then, a dynamic LCA tool proportions and assembles the impact category indicators of the life cycle by matching the mentioned information's of each layer of the road pavement with the rows of an external database (Excel datasheet) that represent the impact category indicators of each unit disaggregated process of the life cycle.

Therefore, the informative framework aims at achieving an adequate level of detail of the road pavement, which contains not only the geometric information, but also the main characteristics of the materials assigned to the geometries, to estimate, for each pavement alternative the designer wants to analyze, the environmental performance expressed by LCA indicators. For this purpose, several custom property sets were assigned to the BIM model objects, as follows:

- Three property sets, namely Wearing course properties, Binder course properties and Base course properties were assigned each one to the corresponding 3D solids of the BIM model to provide all the additional information to perform a material specific LCA. Each property set involved 20 parameters, of both numeric and text type, which is the minimum amount of information that the authors found appropriate to describe, with sufficient detail, the life cycle of an asphalt material. The text parameters of each asphalt pavement layer are as follows: MixtureType, which indicates simultaneously the production and construction technology (in the present case, the authors provided two different types, HMA, the hot mix asphalt produced in plant and the CMRA, the cold in-place recycled asphalt), CoarseAggregatesType, SandType and FillerType, which indicate the type of coarse aggregates, sand and fillers used in the mixture (two alternatives for each component were provided, namely $\mathrm{T}$, traditional limestone, and $\mathrm{R}$, recycled) and BituminousBinderType, namely NB, which stands for neat bitumen, MB, modified bitumen and $\mathrm{BE}$, bitumen emulsion. The numeric parameters are: MixtureDensity $\left[\mathrm{t} / \mathrm{m}^{3}\right]$, CoarseAggregatesContent, SandContent, FillerContent, RAPcontent [\% by the aggregate distribution], BituminousBinderContent, CementContent, AddedWater [\% by the weight of aggregates], AsphaltMillingProductivity $\left[\mathrm{m}^{3} / \mathrm{h}\right]$, AsphaltLayingProductivity $[\mathrm{t} / \mathrm{h}]$ for HMA or $\left[\mathrm{m}^{2} / \mathrm{h}\right]$

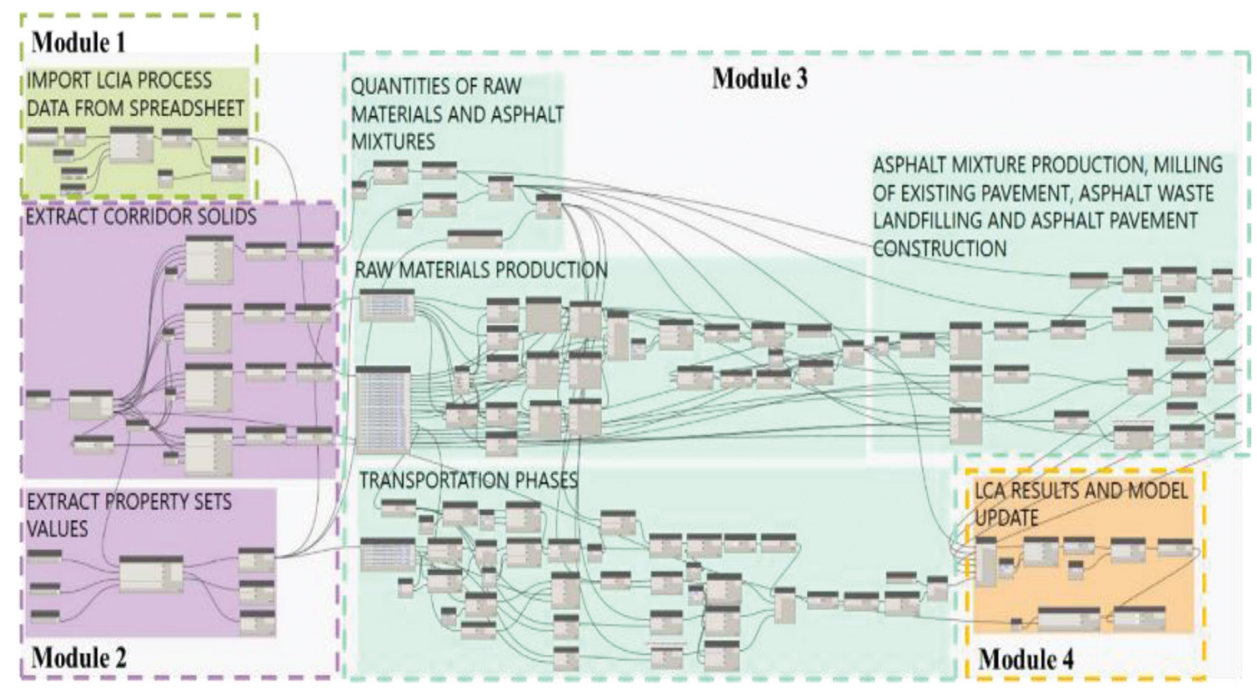

Figure 2: Overview of the visual script for LCA calculations developed in Dynamo. 
for CMRA, DistanceQuarryAsphaltProduction, DistanceRefineryPlantByRoad, DistancePlantSite, DistanceSiteLandfill [km] and DistanceRefineryPlantByShip [NM].

- One property set, LCA indicators, was assigned to the corridor. It involves the $18 \mathrm{ReCiPe}$ midpoint impact category indicators of the life cycle of the asphalt pavement, mentioned in the Methods Section; the properties were initially set equal to zero as a default value and then updated after running the LCA tool.

In addition to the information integrated in the model, an external database was created with the 18 midpoint EIIs of all the unit disaggregated processes of the life cycle according to the assumptions stated in the Methods Section (and can easily be updated by the users via Excel datasheet to make data more representative of the geographical and technological context under analysis).

To establish an automated link between the disaggregated LCA database (MS Excel) and the BIM model (Autodesk Civil3D), a custom script (see Fig. 2) was developed using visual scripting software (Autodesk Dynamo), which extracts the information from the BIM model (such as areas, volumes, materials and materials property sets) and applies changes basing on conditions set through code scripts.

The visual script represented in Fig. 2 consists of four modules that gather the needed information from the BIM model and external data sources, perform the LCA calculation and return several impact assessment indicators that are automatically uploaded as custom userdefined properties in the BIM model. In detail, the four modules are as follows:

- Module 1 imports an Excel LCIA data spreadsheet in the workspace that provides the values of the embodied ReCiPe midpoint indicators for each disaggregated unit process of the life cycle of an asphalt pavement. The data imported trough the code block Data. ImportExcel are organized into a multi-dimensional list, in which each sublist is made of 18 midpoint impact indicators of a disaggregated process of the life cycle. Figure 3 shows the imported list of indicators as it appears in the Dynamo programming environment after the execution of the script.

- Module 2 provides the extraction of the solid volumes that make up the road pavement, namely the wearing, binder, base and subbase course. Moreover, the property sets updated into the BIM model, which provide a design-specific bill of quantities for the various road layers (i.e., type of aggregates, binders, mix design parameters, production and construction technologies, supply distances), are imported in the programming workspace as an input for LCA calculations. These operations are included in a custom node named GetPropertySetValues, which also exports the property sets as an Excel spreadsheet, allowing the user to easily update the information if needed. Figure 3 shows the updated lists of volumes and property sets of the road materials imported in the programming environment after running the script.

- Module 3 performs the LCA calculations based on both the geometric and custom information contained in the BIM model and the imported datasheet according to Eq. 1, gathering the information from both modules 1 and 2 and calculating the relative set of environmental indicators of each process of the life cycle of the asphalt pavement under analysis, as shown in Fig. 3.

- Module 4 sums the LCA results of each process of the life cycle of each asphalt layer into a single set of EIIs and assigns them to the mentioned LCAindicators property set (or updates them dynamically after any change in the pavement solution). Figures 3 and 4 show the updated list of the LCA property sets, as it appears respectively in the programming environment and in the pavement's property set panel of the Civil3D environment after the execution of the script. 


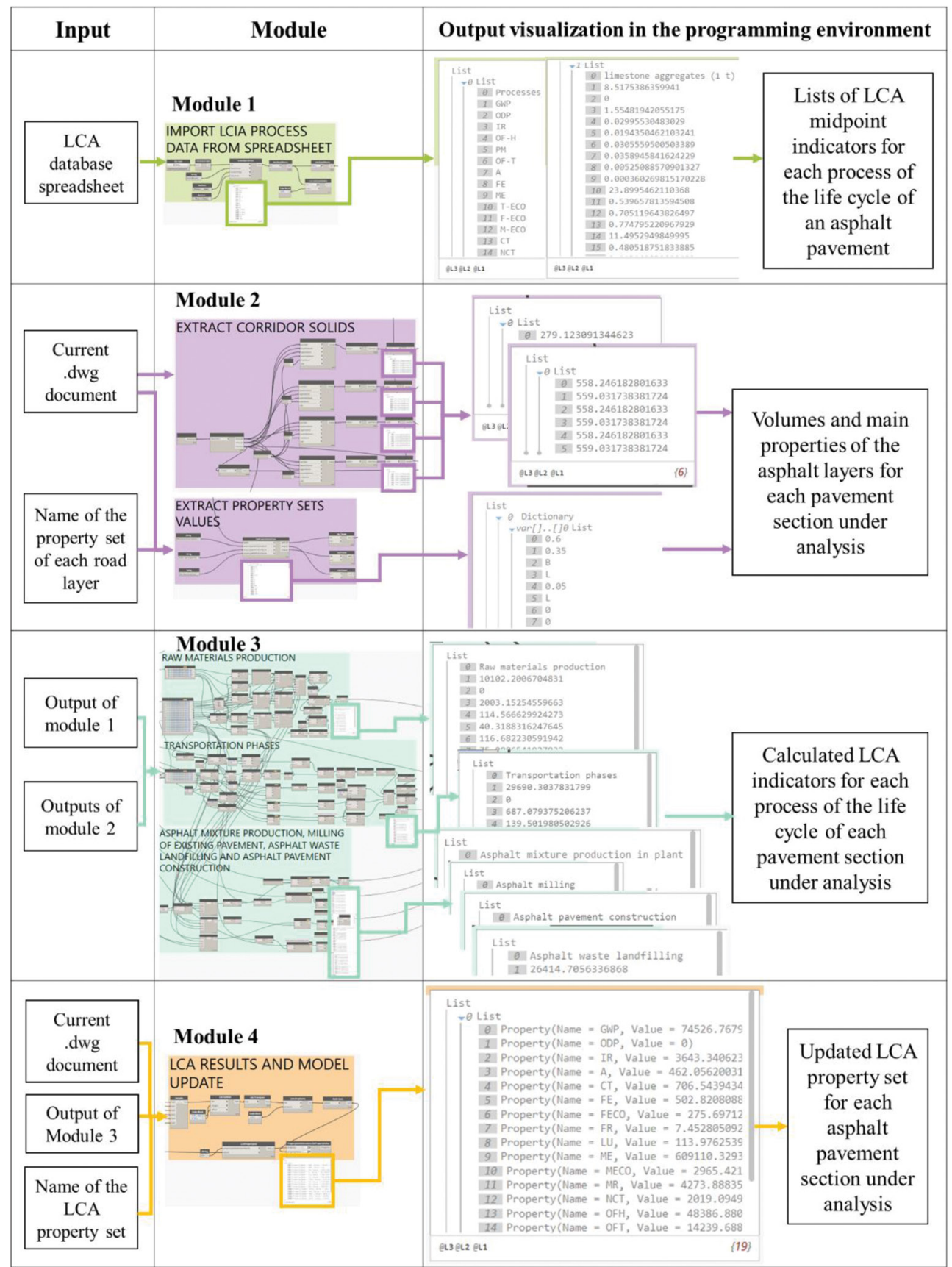

Figure 3: Visualization of the outputs of the main modules of the script as seen in the Dynamo environment and relative inputs. 


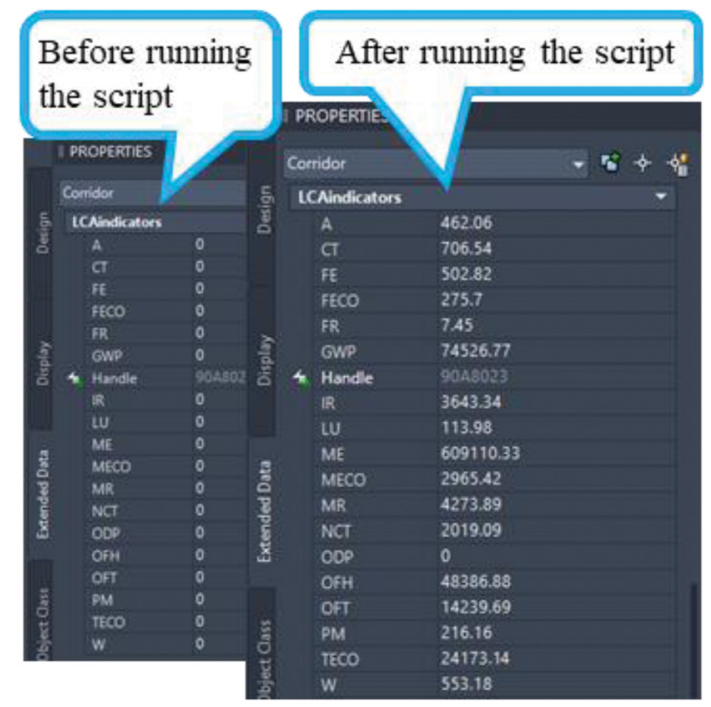

Figure 4: Element's property set panel before and after running the script, showing updated set of LCA indicators.

So, the script provided an LCA framework that has the following features: it is automatic (reads the information directly from the BIM model and does not require any manual inputs except updating the custom parameters), dynamic (updates the results and the consequent data output contextually to any changes in the model, in terms of geometry and additional properties), multi-indicator (returns the values of 18 internationally-recognized EIIs involving different environmental issues) and flexible (leaves to the user the choice of the parameters to be specified, for the remaining adopts the default values used by the authors).

\section{CONCLUSIONS}

With the concepts of sustainability and life cycle thinking becoming more important in the field of asphalt pavements, designers are expressing a growing need for delivering sustainable pavements, analyzed through LCA. At the same time, BIM tools can facilitate and automate the management of complex information in infrastructure projects and converge toward sustainable decision-making strategies. However, a sustainability assessment is a complex process and an integrated approach for implementing sustainable aspects in the asphalt pavement design decision-making process is currently lacking.

The present work provides a simple yet effective framework to help assess the potential environmental impact of an asphalt pavement construction/maintenance treatment, expressed with multiple EIIs calculated according to LCA methodology. The proposed LCA tool expands the current knowledge on BIM-LCA integration oriented toward the promotion of sustainable pavement recycling practices. 


\section{ACKNOWLEDGEMENTS}

The research was developed within the Project of National Interest - PRIN 2017 "Stone Pavements. History, Conservation, Valorisation and Design" (20174JW7ZL) financed by the Ministry of Education, University and Research (MIUR) of the Italian Government.

\section{REFERENCES}

[1] Ruiz, A. \& Guevara, J., Environmental and economic impacts of road infrastructure development: Dynamic considerations and policies. Journal of Management in Engineering, 36(3), 04020006, 2020.

[2] Cass, D. \& Mukherjee, A., Calculation of greenhouse gas emissions for highway construction operations by using a hybrid life-cycle assessment approach: case study for pavement operations. Journal of Construction Engineering and Management, 137(11), pp. 1015-1025, 2011.

[3] Petit-Boix, A., Llorach-Massana, P., Sanjuan-Delmás, D., Sierra-Pérez, J., Vinyes, E., Gabarrell, X., Rieradevall, J. \& Sanyé-Mengual, E., Application of life cycle thinking towards sustainable cities: A review. Journal of Cleaner Production, 166, pp. 939-951, 2017.

[4] Vega, A.D.L., Santos, J. \& Martinez-Arguelles, G., Life cycle assessment of hot mix asphalt with recycled concrete aggregates for road pavements construction. International Journal of Pavement Engineering, pp. 1-14, 2020.

[5] Santos, J., Bryce, J., Flintsch, G., Ferreira, A. \& Diefenderfer, B., A life cycle assessment of in-place recycling and conventional pavement construction and maintenance practices. Structure and Infrastructure Engineering, 11(9), pp. 1199-1217, 2015.

[6] Van Eldik, M.A., Vahdatikhaki, F., Dos Santos, J.M.O., Visser, M. \& Doree A., BIM-based environmental impact assessment for infrastructure design projects. Automation in Construction, 120, 103379, 2020.

[7] Oreto C., Massotti L., Biancardo S.A., Veropalumbo R., Viscione N., Russo F. BIM-Based Pavement Management Tool for Scheduling Urban Road Maintenance. Infrastructures, 6(11), 148, 2021.

[8] Biancardo S.A., Viscione N., Cerbone A., Dessì E. Jr. BIM-Based Design for Road Infrastructure: A Critical Focus on Modeling Guardrails and Retaining Walls. Infrastructures, 5(7), 59, 2020.

[9] Hu, Y., Castro-Lacouture, D. \& Eastman, C.M., Holistic clash detection improvement using a component dependent network in BIM projects. Automation in Construction, 105, 102832, 2019.

[10] Tang, F., Ma, T., Guan, Y. \& Zhang, Z., Parametric modeling and structure verification of asphalt pavement based on BIM-ABAQUS. Automation in Construction, 111, 103066, 2020.

[11] Safari, K. \& AzariJafari, H., Challenges and opportunities for integrating BIM and LCA: methodological choices and framework development. Sustainable Cities and Society, 102728, 2021.

[12] Liu, Y., Van Nederveen, S., Wu, C. \& Hertogh, M., Sustainable infrastructure design framework through integration of rating systems and building information modeling. Advances in Civil Engineering, 8183536, 2018.

[13] Antón, L.Á. \& Díaz, J., Integration of life cycle assessment in a BIM environment. Procedia Engineering, 85, pp. 26-32, 2014.

[14] Kaewunruen, S., Sresakoolchai, J. \& Zhou, Z. Sustainability-based lifecycle management for bridge infrastructure using 6d BIM. Sustainability, 12(6), 2436, 2020. 
[15] Slobodchikov, R., Bakke, K. L., Svennevig, P. R. \& O’Born, R. Implementing climate impacts in road infrastructure in the design phase by combining BIM with LCA. IOP Conference Series: Earth and Environmental Science, 323(1), 012089, 2019.

[16] Wernet, G., Bauer, C., Steubing, B., Reinhard, J., Moreno-Ruiz, E. \& Weidema, B., The ecoinvent database version 3 (part I): overview and methodology. The International Journal of Life Cycle Assessment, 21(9), pp. 1218-1230, 2016.

[17] Blomberg, T., Barnes, J., Bernard, F., Dewez, P., Le Clerc, S., Pfitzmann, M. \& Taylor, R., Life cycle inventory: Bitumen. European Bitumen Association, Brussels, BEL, 2011. Online, www.eurobitume.eu/fileadmin/pdf-downloads/LCI\%20Report-Website2ndEdition-20120726.pdf. Accessed on: 30 Jul. 2021.

[18] U.S. Environmental Protection Agency. '11.1 Hot Mix Asphalt Plants'. Supplement to: Compilation of Air Pollutant Emission Factors. Volume I: Stationary Point and Area Sources. AP-42, 4th Edition. United States Environmental Protection Agency, Office of Air Quality Planning and Standards, Research Triangle Park, North Carolina, 2004. Available at: http://www.epa.gov/ttn/chief/ap42/. Accessed on: 30 Jul. 2021.

[19] Huijbregts, M.A.J., Steinmann, Z.J.N., Elshout, P.M.F., Stam, G., Verones, F., Vieira, M., Zijp, M., Hollander, A. \& Van Zelm, R., ReCiPe2016: a harmonized life cycle impact assessment method at midpoint and endpoint level. The International Journal of Life Cycle Assessment, 22, pp. 138-147, 2016. 